\title{
Nem tão longe, nem tão perto! Notas de um antropólogo brasileiro sobre igualdade e hierarquia em Portugal
}

Edilson Márcio Almeida Silva ${ }^{1}$

Universidade Federal Fluminense

Resumo: Este paper tem por objetivo discutir as representações que acompanham determinados cursos de ação observados pelo autor durante a realização de um estágio pós-doutoral em Portugal. Com base no relato de experiências pessoais e no iálogo com trabalhos que se ocupam etnograficamente do binômio igualdade/hierarquia, o artigo se propõe a analisar situações que, no plano das ideias e valores, ora aproximam, ora distanciam portugueses e brasileiros.

Palavras-chave: igualdade; hierarquia; Portugal; Brasil.

${ }^{1}$ Professor Associado I do Departamento de Antropologia e professor permanente do Programa de Pós-Graduação em Antropologia da UFF. Mestre e doutor em Antropologia (2000 e 2007), também pela UFF, com pós-doutorado em Sociologia pela Universidade Nova de Lisboa. 


\title{
Neither so far nor so close! Notes from a Brazilian anthropologist on equality and hierarchy in Portugal
}

\begin{abstract}
This paper aims to discuss the representations that follow determined action courses as seen by the author during a period of postdoctorate in Portugal. Based on personal experience reports and in dialogue with works that explore ethnographically the pair equality/hierarchy, this paper also aims to analyse situations that, in terms of ideas and values, sometimes brings Brazilians and Portuguese closer and sometimes distances them.
\end{abstract}

Keywords: equality; hierarchy; Portugal; Brazil.

\section{!Ni tan lejos ni tan cercai Notas de un antropólogo brasilero sobre igualdad y jerarquía en Portugal}

\begin{abstract}
Resumen: Este paper tiene por objetivo discutir las representaciones que acompañan determinados cursos de acción observados por el autor durante la realización de una pasantía posdoctoral en Portugal. Con base en el relato de experiencias personales y en el diálogo con trabajos que se ocupan etnográficamente del binomio igualdad/jerarquía, el artículo se propone analizar situaciones que, en términos de las ideas y los valores, ora aproximan, ora distancian a portugueses y a brasileros.
\end{abstract}

Palabras clave: igualdad; jerarquia; Portugal; Brasil. 
$\mathrm{E}$ ntre os anos de 2011 e 2012, realizei um estágio pós-doutoral em Portugal, no âmbito de um convênio firmado entre a Universidade Federal Fluminense (UFF) e a Universidade Nova de Lisboa (UNL)2. Àquela altura, pretendia compreender como a mídia portuguesa, mais especificamente a grande imprensa de Lisboa, participava do processo de construção social da(s) 'violência(s)', a fim de estabelecer uma perspectiva comparativa com o que, a esse respeito, se observava no Rio de Janeiro. Partindo do pressuposto de que os jornalistas não são meros informantes do que se passa no mundo, mas também seus intérpretes (que, como tais, têm interesses, ocupam posições, fazem escolhas, definem prioridades e produzem enquadramentos do real), busquei entender como a temática da(s) 'violência(s)' vinha sendo abordada no noticiário português e como era selecionado, em seu interior, o que se considerava mais relevante e, portanto, digno de visibilidade social. Nesse sentido, me interessava, em primeiro lugar, mapear os fenômenos classificados pelos jornalistas sob a denominação de 'violência' ou 'violento(s)'. De forma complementar, buscava identificar que agentes ou atores sociais eram apontados como responsáveis por sua objetivação.

Para dar conta dessas questões, durante pouco mais de três meses, acompanhei o noticiário de dois conhecidos diários portugueses3. Além disso, ao longo de todo o estágio pós-doutoral, realizei entrevistas com jornalistas de diferentes órgãos de comunicação, além de pesquisadores, profissionais das agências de segurança pública e representantes de Organizações Não-Governamentais dedicadas à defesa dos direitos de mulheres, imigrantes, estudantes, professores, idosos, membros da comunidade LGBT, entre outros. Para desenvolver a pesquisa, tive que estabelecer alguns contatos estratégicos e me familiarizar com variados aspectos da cultura local, o que, evidentemente, não se deu de imediato. É, pois, sobre situações envolvendo esse período inicial de adaptação ao modo de vida lusitano que pretendo me ocupar aqui. Com base no relato de experiências pessoais anteriores à realização da pesquisa propriamente dita, assim como no diálogo com trabalhos que se ocupam etnograficamente do binômio igualdade/hierarquia, procuro analisar as representações que acompanham determinados cursos de ação que, no plano das ideias e valores, ora denotam similitudes, ora diferenciam portugueses e brasileiros. Para isso, na primeira parte do artigo, descrevo algumas situações que me impactaram positiva ou negativamente tão logo cheguei a Portugal. Em seguida, apoiado na teoria da hierarquia, de Louis Dumont, contrasto analiticamente certos aspectos da ideologia local com práticas e representações que, em circunstâncias equivalentes, costumam ser acionadas no Brasil.

${ }^{2}$ O convênio CAPES/FCT CGCI o010/2009 foi coordenado pelos professores Roberto Kant de Lima (UFF) e José Manuel Resende (UNL), a quem sou grato pela valorosa experiência. Agradeço, também, ao estímulo do professor Fábio Reis Mota (UFF), um dos responsáveis diretos pela consecução do convênio.

3 Os jornais escolhidos como base empírica para a pesquisa foram o Diário de Notícias e o Correio da Manhã, dois dos mais importantes generalistas de Portugal. Os periódicos adotam políticas editoriais notadamente distintas, haja vista que estão voltados para segmentos de classe e públicos-alvo diferentes. 


\section{Em Portugal com os portugueses}

Conforme o previsto, por volta das $23 \mathrm{~h} 30$ do dia 25 de novembro de 2011, desembarquei no Aeroporto de Lisboa ${ }^{4}$. A bordo de um taxi, de lá me dirigi para o local em que viria a residir durante os próximos seis meses, tempo que duraria o meu estágio pós-doutoral. Pouco depois da meia-noite já me encontrava na aprazível Rua da Bica de Duarte Belo, popularmente conhecida como Rua da Bica5. Da sacada do apartamento avistava praticamente toda a sua extensão ao passo que, durante alguns minutos, me entretinha com a música e o alarido das centenas de pessoas que, em clima de intensa sociabilidade, ali se reuniam. Embora o cenário se mostrasse convidativo, após dez extenuantes horas de viagem, optei por me recolher, tomar um banho e assistir um pouco de TV. Chegava a Portugal um dia depois de uma greve geral deflagrada em protesto contra o conjunto de medidas de austeridade recentemente anunciadas pelo governo ${ }^{6}$. A exemplo de outros países europeus, como Grécia, Espanha e Irlanda, Portugal atravessava uma grave crise econômica e esse era um dos temas mais frequentes na programação televisiva.

Ao ligar a TV me defrontei com um acalorado debate que tinha, de um lado, membros da Igreja Católica e, de outro, representantes da sociedade civil organizada, tais como a Associação Cívica República e Laicidade. Eles discutiam quais, dentre os 14 feriados nacionais, deveriam ser cancelados em prol do combate à crise7. Zapeando em busca de outras atrações uma curiosidade reteve, por alguns instantes, a minha atenção: o horário de exibição dos programas. Ao percorrer a grade de horários da emissora que assistia, me dei conta de que um de seus telejornais estava programado para começar às 18ho3, uma telenovela, às 19h17, um talk show, às $20 h 41 \mathrm{e}$ assim por diante. Raras eram as atrações que tinham início em horários "cheios", isto é, às $8 \mathrm{~h}, 9 \mathrm{~h}, 10 \mathrm{~h}$ etc. E isso, conforme pude averiguar, não ocorria apenas com aquela emissora. Pelo contrário, a programação dos concorrentes seguia o mesmo padrão, organizando-se, também, com base em horários "quebrados". Mas, o que realmente chamou a minha atenção foi o fato de que tais horários costumavam ser rigorosamente respeitados. Assim, caso um programa estivesse previsto para começar às 19h17, o seu início ocorreria, impreterivelmente, às 19h17, algo bastante diferente do que ocorre no Brasil, sobretudo nos canais da chamada TV aberta.

Se os horários quebrados e o seu estrito cumprimento já haviam chamado a minha atenção, ainda mais impactado fiquei ao me dar conta de que tal característica não dizia respeito unicamente à programação da TV. Conforme pude atestar, essa forma peculiar de lidar com o tempo perpassava diferentes domínios da vida social portuguesa, fazendo-se notar, inclusive, na dinâmica de funcionamento dos transportes públicos. Durante o tempo que permaneci em Lisboa, observei que, em alguns bairros (como o de Belém, por exemplo), os pontos de ônibus ou, como dizem por lá, as paragens dos autocarros, dispunham de painéis

\footnotetext{
4 Também conhecido como Aeroporto da Portela, o Aeroporto de Lisboa passou a ser oficialmente denominado, a partir de 2016, de Aeroporto Humberto Delgado.

5 A Rua da Bica de Duarte Belo situa-se nas proximidades do Bairro Alto Lisboa, sendo conhecida por seus inúmeros bares, suas casas e prédios com estendais nas varandas, assim como pelo seu famoso ascensor (o Elevador da Bica) que, desde 1892, liga a Travessa do Cabral ao Largo do Calhariz.

${ }^{6}$ A greve ocorreu alguns dias antes da votação do orçamento de 2012 pelo Parlamento português que, entre outras medidas, previa a supressão temporária dos pagamentos extras para funcionários públicos e pensionistas com rendas superiores aos 1.000 euros e o aumento da jornada de trabalho no setor privado.

$7 \mathrm{O}$ resultado dessa controvérsia pública foi o cancelamento de quatro feriados, dois civis e dois religiosos: Proclamação da República ( 5 de outubro), restauração da independência ( $1^{\circ}$ de dezembro), Dia de Todos os Santos ( $1^{\circ}$ de novembro) e Corpus Christi, celebrado 60 dias depois do domingo de Páscoa.
} 
informando a hora em que estes passariam. E tudo segundo o mesmo padrão da TV, isto é, com horários quebrados e uma irrepreensível pontualidade. É claro que, eventualmente, podia haver um ligeiro atraso, mas nada além disso.

Um aspecto interessante em relação à gestão e organização do tempo entre os portugueses é que, em se tratando de uma cidade turística como Lisboa, o fluxo de passageiros nos transportes públicos coletivos tende a ser intenso, o que, não raro, obriga os autocarros a permanecerem estacionados nas paragens por períodos relativamente longos, de modo que todos os passageiros possam embarcar e/ou desembarcar com tranquilidade. O curioso, no caso, é que independentemente do tempo que um veículo permaneça estacionado, ele de modo algum é ultrapassado pelos que veem em seguida. Observando rigorosamente a ordem de chegada ao ponto, cada veículo aguarda o da frente concluir o embarque/desembarque de passageiros para só então realizar tais procedimentos. Não me preocupei à época em me informar se isso era uma prática formalmente regulada pelas empresas ou se havia alguma legislação sobre o assunto, mas, em se tratando de um olhar impressionista (como, de resto, é o que orienta toda a primeira parte deste trabalho), não tive como deixar de estabelecer uma perspectiva contrastiva com o que a esse respeito se verifica em capitais brasileiras, como o Rio de Janeiro. Nesta cidade, as ultrapassagens são relativamente frequentes (inclusive, quando envolvem veículos da mesma linha) e, muitas vezes, estão associadas a relações jocosas nas quais, estimulados pelos cobradores, motoristas estabelecem verdadeiras disputas com seus colegas para ver quem chega primeiro ao ponto final ou à garagem da empresa.

Conforme notei em um sem-número de oportunidades, o respeito à ordem de chegada permeia, também, outros domínios do espaço público português, como deixa ver o episódio que se segue. Certa noite, a exemplo do que fazia eventualmente, me dirigi a um shopping center para assistir uma sessão de cinema. Chegando lá, me defrontei com uma fila relativamente longa que se formava diante do único guichê de atendimento em operação. Alguns minutos após a minha chegada, me dei conta de que uma funcionária se dirigia à caixa ao lado, dando a entender que, dentro em breve, o guichê entraria em funcionamento. Uma senhora que se encontrava atrás mim parece ter também atentado para a movimentação da atendente, razão pela qual, disfarçadamente, foi se deslocando para perto do local. Assim que a funcionária pôs a caixa em funcionamento, ela se colocou diante do guichê, preparando-se para assumir aquele que seria o primeiro lugar da fila. De forma educada, mas taxativa, a atendente explicou que a fila ao lado seria desmembrada em duas, de modo a que, com isso, se respeitasse a ordem de chegada dos clientes. Fazendo-se de desentendida, a senhora argumentou que tinha acabado de chegar e, ao avistar a abertura do guichê, julgou natural dar início a uma nova fila, o que, segundo o seu entendimento, não traria prejuízo a quem quer que fosse. A funcionária, por sua vez, respondeu que havia observado o deslocamento da senhora rumo ao guichê e, adotando uma postura firme, esclareceu que não lhe permitiria assumir o primeiro lugar na fila, posto que isso implicaria uma forma de favorecimento a ela e, consequentemente, de desrespeito aos direitos dos demais. Após o rápido diálogo com a profissional que, cônscia de suas atribuições, mostrava-se absolutamente irredutível, nada mais parecia restar à senhora, senão retornar ao seu lugar no final da fila.

Exemplos como o supracitado, indicam que o respeito à ordem de chegada constitui um aspecto altamente valorizado no espaço público português. $\mathrm{O}$ mesmo pode ser dito do atendimento individualizado e eficiente que costuma ser oferecido nos estabelecimentos comerciais, repartições públicas e demais órgãos 
de prestação de serviço. Definitivamente, ao longo da minha estada em Portugal, não tive do que reclamar a esse respeito. A única exceção, talvez, refira-se a um episódio ocorrido num local que, por ironia, recebe o nome de Loja do Cidadão. Instaladas por todo o país, as Lojas do Cidadão são centros de atendimento criados pelo governo português, em 1999, com a finalidade de oferecer variados tipos de serviços, públicos e privados ${ }^{8}$, não apenas aos cidadãos locais, mas aos residentes em Portugal, de forma geral. No caso, havia recorrido a uma delas a fim de obter o Número de Contribuinte ou Número de Identificação Fiscal (NIF)9, sem o qual não teria como dispor de direitos básicos como, por exemplo, abrir uma conta bancária. Imbuído desse propósito, busquei a unidade mais próxima da minha residência, o que me levou à Loja do Cidadão dos Restauradores, uma das três que, àquela altura, funcionavam na capital portuguesa ${ }^{10}$. Instalada num imponente edifício de três andares e ocupando uma área de cerca de $1.400 \mathrm{~m}^{2}$, a unidade dispunha de uma capacidade de atendimento de cerca de três mil pessoas por dia. Quando lá cheguei, algumas centenas ocupavam os diferentes pisos do edifício, a maior parte, decerto, aguardando atendimento. Logo, logo viria a me tornar uma delas.

Depois de uma rápida passagem pelo setor de informações, me dirigi a um dos guichês de atendimento, apresentando a minha documentação pessoal e a razão que me levava àquele lugar: o Número de Contribuinte. Após brevíssima inspeção dos papéis, a profissional que me atendia informou que, se eu quisesse estudar em Portugal, teria que procurar diretamente a universidade a que pretendia me vincular. Argumentei que devia haver algum engano, já que eu era um profissional do Magistério Superior e participava de um convênio internacional com recursos públicos oriundos do meu país. Concomitantemente, reapresentei a carta de aceitação definitiva do meu supervisor (assinada em papel timbrado), de modo a comprovar que já possuía um vínculo institucional. Mas, as minhas palavras foram em vão. De forma intransigente, a atendente sequer voltou a olhar a documentação, reiterando que não tinha como me ajudar e que, portanto, eu deveria buscar a Universidade Nova de Lisboa para resolver a situação.

A princípio, cogitei que o mal-entendido tinha derivado da minha ainda pouca familiaridade com alguns códigos locais ${ }^{11}$. Não obstante, por coincidência ou não, o mesmo ocorreu com uma pesquisadora brasileira que, assim como eu, estava em Portugal para realizar um estágio pós-doutoral pelo convênio CAPES/FCT. Na mesma hora em que era atendido, ela se dirigiu a um outro guichê, onde apresentaria demanda e documentação semelhantes às minhas. A exemplo do que se passou comigo, a pesquisadora foi informada que não obteria o Número do Contribuinte no local, recebendo, por conseguinte, a recomendação de que procurasse a sua universidade de destino. Ainda que, nesse caso, a explicação fosse um pouco diferente da que me foi apresentada, fato é que ela também recebeu uma resposta rápida, pouco interessada e negativa à sua solicitação. Isto posto, devo dizer que, embora tenha lido e ouvido comentários elogiosos ao atendimento prestado nas Lojas do Cidadão, definitivamente, não foi essa a impressão

\footnotetext{
8 Dentre os inúmeros serviços fornecidos nas Lojas do Cidadão estão a emissão de passaportes, registros de veículos, certidões de nascimento, casamento e comerciais etc. Além disso, é possível efetuar aí pagamentos de contas de luz, telefone, televisão e internet, além de enviar cartas e encomendas.

9 Em linhas muito gerais, pode-se dizer que o Número de Contribuinte equivale ao Cadastro de Pessoas Físicas (CPF) no Brasil.

${ }^{10}$ A unidade foi fechada em 2013. Segundo reportagem do jornal Expresso, de 30 de dezembro de 2013, os motivos alegados pelo Governo foram os altos custos de manutenção ("mais de 600 mil euros/ano") e o fato de ser, à época, a loja com "mais queixas dos cidadãos quanto à aferição dos serviços prestados".

${ }_{11} \mathrm{Me}$ recordo de, ainda recém-chegado a Portugal, ter ido a uma padaria e perguntado se havia pão francês, recebendo, então, a seguinte resposta: "não, só português". Pouco tempo depois, dessa vez numa mercearia, consultei um funcionário se tinha batata inglesa, ao que ele respondeu: "não, só portuguesa”.
} 
deixada pela unidade dos Restauradores. A julgar pela frieza do tratamento destinado a mim e à referida pesquisadora, não tive como deixar de imaginar o que se passava com imigrantes que, àquela altura, chegavam a Portugal em busca de emprego ou de uma nova pátria para se estabelecer (o que, felizmente, não era o nosso caso!).

Com a negativa à minha demanda, me vi obrigado a buscar uma forma alternativa de solucionar o problema. Foi então que, por meio de contatos com colegas portugueses, vim a saber que, além das Lojas do Cidadão, o Número do Contribuinte também poderia ser obtido numa das lojas de serviço das Finanças da Autoridade Tributária e Aduaneira do Governo de Portugal. Para tanto, bastava que eu me dirigisse a uma de suas unidades acompanhado de um representante fiscal, isto é, de alguém com residência comprovada em território nacional português e que estivesse disposto a subscrever a solicitação. Tendo encontrado quem atendesse a tais exigências, procurei a loja do serviço das Finanças mais próxima. Chegando lá, mais uma vez me deparei com inúmeras pessoas à espera de atendimento, ainda que numa escala menor do que a verificada na Loja do Cidadão. Retirei uma senha e aguardei. Como, a princípio, as cadeiras estavam todas ocupadas, permaneci de pé até que o painel luminoso chamasse o meu número, indicando o guichê em que seria atendido. Uma vez lá, apresentei a minha solicitação e a documentação correspondente. Para a minha satisfação, diferentemente do que havia ocorrido na Loja do Cidadão, a atendente do serviço de Finanças leu com atenção todos os papéis que entreguei, demonstrando não só ter entendido a minha demanda como estar, de fato, interessada em atendê-la. Após passar em revista cada um dos documentos, a profissional emitiu um protocolo que me permitiria retirar, dentro de alguns dias, o Título de Residência no qual constava o almejado Número do Contribuinte.

Até aí, nada demais. Afinal, o serviço foi prestado com eficiência e correção, dentro, portanto, do esperado. Mas, o desfecho inusitado ainda estava por vir. Ao entregar o protocolo, a atendente, num gesto inesperado, solicitou que me aproximasse do guichê e, praticamente sussurrando, disse que, na próxima vez, eu não precisaria pegar senha ou enfrentar fila. Segundo ela, isso tinha a ver com uma informação contida no documento que acabara de me entregar e que, conforme verifiquei, constaria também no meu Título de Residência. Inscrita no campo "OBSERVAÇÕES”, a informação era a seguinte: “ACT. INVESTIGAÇÃO/ALTAM. QUAL. ART.90, N. 1 DA LEI N. 2372007”. Pelo que entendi, a anotação dizia que eu estava em Portugal para fazer pesquisa ou, como dizem por lá, para desenvolver "actividades" de investigação acadêmico-científicas, um ofício reconhecido, inclusive por lei, como altamente qualificado. Por conta dessa anotação, num período de poucos dias (a contar da minha ida à Loja do Cidadão), me vi subitamente erigido da condição de cidadão de segunda classe à de primeira.

Uma outra situação envolvendo formas hierárquicas de tratamento interpessoal ocorreu quando eu ainda tentava estabelecer o primeiro contato para a realização da pesquisa relativa ao estágio pós-doutoral. Conforme mencionado, a pesquisa tinha por objetivo compreender a participação da mídia portuguesa no processo de construção social da(s) 'violência(s)', razão pela qual o meu supervisor me colocou em contato com um jornalista que, àquela altura, cursava o doutorado em Sociologia na Universidade Nova de Lisboa. Por meio de uma mensagem de e-mail, fui apresentado ao periodista que, atendendo à solicitação do colega, gentilmente se colocou à disposição para participar da pesquisa. Feita a mediação, demos início a uma troca de mensagens, nas quais sempre procurei adotar uma postura respeitosa e formal. Depois de algumas semanas de comunicação à 
distância, finalmente marcamos uma reunião no Café da Universidade. Ao nos encontrarmos, discorri em linhas gerais sobre o meu objeto de estudo e a expectativa de constituir uma rede de contatos com profissionais da imprensa local. Após brevíssima troca de ideias, o meu interlocutor me convidou a conhecer uma livraria situada no interior do campus. Lá chegando, fomos recebidos por um simpático funcionário que a ele se dirigia como um velho conhecido. Uma vez apresentados, entabulamos, os três, uma conversa de cerca de vinte minutos sobre os títulos disponíveis que, de algum modo, poderiam contribuir para os meus propósitos. Em meio a sugestões bibliográficas e uma prosa que beirava à informalidade, acabei por cometer um lapso ao me referir ao jornalista, que se chamava João Sousa Pinto ${ }^{12}$, empregando somente os seus primeiro e último nomes, isto é, tratando-o apenas por João Pinto.

Mal havíamos saído do local e, ato contínuo, recebi uma primeira reprimenda: "O meu nome é João Sousa Pinto", disse o periodista. Ainda tentava entender o que acontecia quando fui confrontado com uma segunda colocação, igualmente ríspida: "E a propósito, vocês no Brasil costumam se reportar às pessoas chamando-as de Senhor...”. Intrigado, perguntei, então, como ele achava que deveria ser tratado, ao que recebi a seguinte resposta: "Ora, pois, como Dê Erre [D.R.]”. Dado o imponderável da situação, me vi obrigado a decidir, em poucos segundos, como reagir. Se me calasse, talvez pudesse contar com os préstimos do jornalista para estabelecer a rede de contatos de que precisava para realizar a pesquisa. Mas, para isso, teria que assentir com uma postura autoritária que, a princípio, não me parecia ter qualquer justificativa. Por outro lado, se respondesse à altura, talvez ficasse mais aliviado, mas correria o risco de inviabilizar o trabalho que pretendia desenvolver. Sem tempo para maiores reflexões, me virei para o jornalista e, no mesmo tom empregado por ele, afirmei que o meu nome era Edilson Márcio Almeida da Silva e não apenas Edilson Silva, como costumava ser chamado pelos colegas portugueses. Em seguida, esclareci que estava em Portugal para realizar um estágio pós-doutoral, o que, na prática, significava que já possuía o título de doutor, de modo que se, no caso, alguém merecia um tratamento reverencial, esse alguém era eu e não ele. Por fim, acrescentei que aquele tipo de situação era uma novidade para mim, já que, no meio acadêmico brasileiro, muitos de nós consideramos a ostentação de títulos acadêmicos uma postura vetusta e pernóstica. Surpreendendo-me mais uma vez, o periodista reagiu às minhas colocações com aparente tranquilidade e me convidou a tomar um novo café. Dali em diante, de modo mais solícito, ele ligou o tablet e passou a me apresentar uma série de reportagens que julgava serem do meu interesse, prontificando-se, ainda, a me passar todos os contatos necessários à realização da pesquisa.

\section{Sobre o(s) individualismo(s): breve comentário analítico}

Mas, afinal, qual a razão de ser das situações descritas acima? Seriam meras curiosidades a respeito do povo português e dos seus costumes? Do ponto de vista sociológico, o que delas se pode extrair? Que representações se lhes acompanham? Para tentar dar uma resposta a tais questões, recorrerei à muitas vezes mal compreendida teoria da hierarquia, elaborada por Louis Dumont, procurando dialogar, também, com alguns autores que, direta ou indiretamente, nela 
encontraram inspiração para os seus trabalhos.

Em linhas gerais, o arcabouço teórico dumontiano se define a partir da contraposição entre o holismo - tido como uma ideologia ${ }^{13}$ própria de sociedades tradicionais, nas quais a hierarquia se apresenta como o mais importante traço distintivo - e o individualismo - caracterizado como a ideologia dominante nas sociedades modernas, em que a noção de igualdade se apresenta como elemento primordial. Segundo tal perspectiva, o pressuposto básico do holismo é o de que há na totalidade social algo mais do que nas suas partes constitutivas ou na soma destas, de modo que, nesse caso, a sociedade é representada como hierarquicamente superior aos indivíduos que a compõem. Já a representação valorizada no individualismo é a de que, por trazer dentro de si a essência da humanidade, o "indivíduo é quase sagrado, absoluto; não possui nada acima de suas exigências legítimas; seus direitos só são limitados pelos direitos idênticos dos outros indivíduos" (DUMONT, 1992: 52-3). Mas, se ater à construção da oposição, nestes termos, implica em considerar tal modelo analítico de forma simplista e esquemática, deixando de lado os seus potenciais desdobramentos. Senão, vejamos.

Historicamente, a emergência do individualismo e sua transformação na ideologia dominante nas sociedades ocidentais modernas estão associadas a importantes transformações sociais, políticas e econômicas ocorridas na Europa a partir do século XV. Tendo se expandido por diversos países ao longo do tempo, a ideologia individualista jamais se apresentou, porém, como uma realidade "uniforme para todos os sujeitos submetidos a sua influência, em cada período de sua história e em cada formação nacional ou regional" (DUARTE, 2017: 741). Tanto em termos teóricos quanto práticos, a sua difusão se processou consoante à premissa de que toda configuração ideológica é sui generis, dado que, em cada uma, "ideias e valores são hierarquizados de um modo particular" (DUMONT, 1985: 259). Nesse sentido, enquanto "variante nacional" da ideologia moderna, o individualismo português se apresenta como especialmente favorável ao estabelecimento de um olhar contrastivo com o universo ideológico brasileiro no qual, conforme assinala Da Matta (1990), o individualismo igualitário e o holismo hierárquico convivem lado a lado, simultaneamente e de forma complementar.

Tal qual mencionado, a importância conferida à concepção de indivíduo como valor moral atravessa diferentes domínios da vida social portuguesa, o que, cabe ressaltar, chamou a minha atenção nas mais variadas circunstâncias. Inicialmente, uma das que me soaram mais inabituais dizia respeito ao funcionamento dos transportes públicos coletivos. Pelo que pude observar, em Portugal, estes se destinam a todo e qualquer cidadão, abrangendo, assim, os mais diversos usuários (que o utilizam apenas eventualmente) e utentes ${ }^{14}$ (que dele fazem uso rotineiro, logo, necessário, constante e interessado), o que produz um efeito digno de nota no contexto em tela, qual seja: o rigoroso cumprimento dos horários. Tal cumprimento permite a quem vive ou, por qualquer razão, se encontra em Portugal dispor de certa previsibilidade no que tange aos fluxos urbanos, de modo a, com isso, planejar as suas atividades cotidianas e, portanto, otimizar a organização do próprio tempo, o que, salvo melhor juízo, constitui inequívoca expressão de respeito aos direitos individuais.

A exemplo do que se passa no Brasil (embora não da mesma forma, nem na mesma ordem de grandeza), o transporte público português se concentra no setor

${ }_{13}^{13}$ Dumont (2000: 29) chama de ideologia "o conjunto de ideias e valores - ou representações - comuns em uma sociedade ou correntes em dado meio social".

${ }_{14}$ Utilizo a distinção entre utente e usuário conforme proposto em MELLO, Marco Antônio da Silva; VOGEL, Arno. Lições da rua (ou quando a rua vira casa): algumas considerações sobre habito e diligo no meio urbano, 1981. Disponível em: $<$ http://lemetro.ifcs.ufrj.br/licoes_da_rua.pdf >. 
rodoviário. Entretanto, dadas a qualidade e a eficiência do setor em Portugal, pode-se dizer que essa talvez seja uma das poucas coincidências existentes na realidade dos dois países. Os atributos do transporte de massas em Portugal, que noutras circunstâncias seriam naturalizados, chamam a atenção exatamente pelo contraste com o quadro vivido por milhões de pessoas nas mais diversas localidades do Brasil. Ao contrário do que se passa com os portugueses, de um modo geral, o transporte público brasileiro é considerado ruim e ineficiente. As passagens são caras, os veículos apresentam condições precárias, circulam frequentemente lotados e impõem um grande tempo de espera aos passageiros. Isso sem mencionar a falta de pontualidade e as inumeráveis horas de trabalho perdidas no trânsito ${ }^{15}$, o que leva muitos especialistas a tratarem a questão a partir da oposição massa X elite.

Em capitais brasileiras como o Rio de Janeiro, por exemplo, tal oposição tende a assumir grande relevo, uma vez que, enquanto os ônibus e trens circulam por praticamente toda a parte (inclusive, pelas regiões mais pobres da cidade), as linhas de metrô cobrem apenas as chamadas "áreas nobres". Para além da ênfase histórica conferida ao rodoviarismo, não há como deixar de reconhecer que o alcance dos diferentes modais de transporte reflete um corte de classes que se faz sentir, inclusive, territorialmente. Longe de se tratar de um caso isolado, o que se verifica no Rio de Janeiro acontece, também, em outras regiões metropolitanas do Brasil, nas quais o transporte público coletivo não é destinado aos indivíduos em geral, mas a um segmento populacional específico: a grande massa de trabalhadores que dele precisam para se deslocar diariamente. Como coloca Da Matta (1993: 194-5), nas grandes cidades brasileiras, a necessidade de viajar de ônibus e/ou de trens representa "um dos mais acabados sinais de um estilo de vida subalterno, inferior ou pobre", razão pela qual "ser usuário de transporte público é, no caso do Brasil, o ponto final de uma massificação que todos tentam evitar". Pode-se dizer que, por aqui, além de atentarem contra a dignidade de amplos segmentos de trabalhadores, as condições da oferta desse tipo de serviço concorrem para a expropriação do seu tempo livre, sendo que "o tempo livre, para essas massas, diz respeito ao seu próprio corpo e ao seu uso como instrumento de sobrevivência na cidade". Outrossim, não chega a haver propriamente exagero em se afirmar que, aliada às múltiplas mazelas com que se defronta no dia a dia, "a deficiência dos meios de transporte urbano constitui uma sobre-exploração do usuário deste sistema”.

A exemplo do que se passa nos transportes públicos coletivos, o individualismo português se faz notar, também, no respeito às filas, que estão espalhadas por toda a parte: nas paragens dos autocarros, nas bilheterias do metrô, nas caixas dos bares, teatros, supermercados etc. Certa feita, ao adentrar uma farmácia no bairro do Chiado, em Lisboa, me dirigi a um funcionário para consultá-lo sobre o preço de determinado produto, sendo informado que deveria aguardar, uma vez que ele estava atendendo uma outra cliente. Como não tinha avistado ninguém diante do balcão, sequer me dei conta da presença de uma senhora que transitava calmamente pelo interior da farmácia, observando e manipulando produtos diversos. Aparentemente, ela ainda não havia solicitado nada ao funcionário e, a bem da verdade, nem sei se esboçou qualquer ação nesse sentido. Mas, pelo que entendi, isso era algo desnecessário. Embora não houvesse uma fila objetivamente formada (ou, ao menos, não numa forma reconhecível para mim),

${ }_{15}$ É evidente que, no Brasil, a qualidade dos transportes públicos coletivos varia sensivelmente de região para região. Embora seja uma exceção à regra geral, há que se mencionar que cidades como Curitiba, por exemplo, dispõem de uma rede de transporte de massas comparativamente superior ao de outras capitais. 
tudo dava a entender que, segundo os códigos locais, o simples fato de a senhora ter entrado primeiro no estabelecimento seria condição suficiente para que a fila viesse a se constituir.

Embora a banalização cotidiana da fila contribua para que a sua importância sociológica seja ignorada, há que se reconhecer que ela constitui um indelével instrumento de ocupação igualitária do espaço público. Por definição, sua razão de ser repousa sobre um princípio de ordem ética segundo o qual quem chega antes tem o direito legítimo de ficar na frente. É isso o que nos mostra, não só o episódio da farmácia, como o da fila do cinema, em que uma atendente repreendeu uma senhora que pretendia furar a fila dos ingressos, mandando-a de volta ao seu lugar. Entre outras razões, este episódio parece emblemático por afirmar a preeminência da igualdade tanto entre os integrantes da fila, como entre as partes envolvidas na querela, quais sejam: a que atendia e a que era atendida. Contrariando uma ideia corrente no Brasil - a de que o cliente tem sempre razão -, a funcionária do cinema adotou uma postura refratária à pretensa superioridade da sua interlocutora, demonstrando, assim, ter absoluta clareza de que estava ali para trabalhar, não para servir (o que, diga-se de passagem, é bem diferente ${ }^{16}$ ).

Se, como mencionado, a fila corresponde a uma forma de ocupação igualitária do espaço público, dependendo dos usos que se lhe impõem, ela também pode servir para demarcar fronteiras, reforçando, assim, a existência de distâncias sociais. Quero dizer com isso que do mesmo modo que o respeito à fila iguala os indivíduos, o seu descumprimento os hierarquiza e, consequentemente, desiguala. Essa inversão pode ser verificada, por exemplo, no episódio envolvendo o serviço das Finanças, quando fui dispensado de enfrentar uma fila, o que me colocou diante de uma forma de classificação social que não condizia com as habituais manifestações igualitárias dos portugueses. Naquele contexto, eu me encontrava diante de uma inequívoca situação de privilégio que, como bem sabemos, constitui um traço característico do holismo hierárquico. Sendo assim, como se falar, então, de um individualismo à portuguesa? De acordo com Dumont (2000: 35), isso seria possível porque, em princípio, toda ideologia constitui "uma unidade que não exclui, todavia, a contradição ou o conflito”. Noutras palavras, isso quer dizer que assim como a igualdade plena corresponde a uma espécie de idealização, não há como uma relação de superior com inferior se estabelecer de forma absoluta de uma ponta à outra da experiência, já que "aquilo que era superior num nível superior pode se tornar inferior num nível inferior” (DUMONT, 1992: 373-4).

É evidente que a discriminação positiva de pessoas que, por conta da sua posição social, são dispensadas de enfrentar filas também faz parte da realidade brasileira. Mas, por aqui, isso não se dá necessariamente da forma acanhada que observei em Portugal. No Brasil, somos cotidianamente confrontados com filas e com formas de excepcionalização da sua natureza igualitária. Veja-se, nesse sentido, o caso dos bancos que disponibilizam salas, gerentes e caixas à parte para os clientes que rendem mais e são, portanto, classificados como "especiais". Em casos como esse, as filas até continuam a existir, mas definitivamente não são as mesmas para todos. Desse modo, ao invés de igualar, elas acabam por reforçar concepções seletivas, diferenciadas e excludentes de relações sociais.

Pesquisadores como Kant de Lima (2000) e Oliveira (2011) têm apontado a coexistência, no Brasil, de duas diferentes formas de lidar com a igualdade: uma

\footnotetext{
${ }^{16}$ Reconheço, aqui, a inspiração do trabalho de O' Donnel (1986), em que ele contrasta a solicitude, simpatia e distanciamento social característicos de profissionais como garçons, empregados de lojas e motoristas de táxi no Rio de Janeiro e a postura distinta adotada por seus equivalentes em Buenos Aires.
} 
baseada nas diferenças e outra, nas semelhanças. O primeiro sentido (o da igualdade na diferença) corresponde àquele que empregamos formalmente quando, apoiados no Artigo $5^{\circ}$ da Constituição Federal Brasileira de 1988, afirmamos que todos somos iguais perante a lei, sem distinção de qualquer natureza. Nesse caso, temos em mente o mundo cívico moderno, idealmente concebido, no qual todos os indivíduos, a despeito das suas diferenças substantivas, são entendidos como destinatários dos mesmos direitos, ou seja, de um tratamento uniforme e sem discriminações por parte das instituições jurídico-políticas. Já o segundo sentido (o da igualdade na semelhança) tem como referência a célebre frase do jurista Rui Barbosa, extraída da obra "Oração aos moços", na qual se afirma que a verdadeira igualdade consiste em tratar igualmente os iguais e desigualmente os desiguais na medida em que estes se desigualam. Diferentemente da primeira, essa concepção implica na adoção de tratamentos diferenciados aos indivíduos conforme suas semelhanças substantivas (de classe, étnico-racial, de origem, etc.), o que leva, entre outras consequências, à justificação de privilégios. Como exemplos da concepção de igualdade na semelhança, no Brasil, pode-se mencionar o instituto da prisão especial e o foro por prerrogativa de função (também chamado de foro privilegiado), que concede a determinadas pessoas o direito de serem julgadas por Órgãos Superiores da Jurisdição em virtude dos cargos que ocupam ou das funções que exercem.

Analiticamente, a possibilidade de se conferir tratamentos privilegiados a indivíduos e/ou grupos, mesmo em contextos igualitários, está relacionada ao fato de que a hierarquia das ideias tem na inversão uma de suas propriedades fundamentais. Tal inversão ocorre à medida em que "uma ideia que cresce em importância e em status, adquire a propriedade de englobar o seu contrário" (DUMONT, 1985: 259). Sem sombra de dúvidas, esse constitui o aspecto mais rico e dinâmico do modelo analítico desenvolvido por Dumont. Por seu intermédio pode-se melhor compreender como se dão a coexistência, a alternância e a sucessão, dentro de um mesmo universo social, entre formas igualitárias e formas hierárquicas de relacionamento social. Em meio às situações aqui descritas, o princípio de englobamento do contrário se faz notar, por exemplo, na intermitência das formas de tratamento a que fui submetido quando recorri à Loja do Cidadão e ao serviço das Finanças para obter o Número de Contribuinte. Tal qual procurei assinalar, enquanto no primeiro caso fui tratado com certo descaso, isto é, como um cidadão de segunda categoria, no segundo, recebi um atendimento privilegiado que me colocava numa condição virtualmente superior à dos demais clientes.

Contudo, o episódio que me apresentou de forma mais patente a intricada convivência entre igualdade e hierarquia em Portugal foi o que envolvia o jornalista com quem conversei na fase inicial do estágio pós-doutoral. Conforme mencionado, o periodista que, à época, cursava o doutorado em Sociologia na Universidade Nova de Lisboa, ficou visivelmente contrariado ao ser tratado como Senhor e não como Dê Erre [D.R.], razão pela qual se arvorou o direito de demandar um tratamento condizente com o seu suposto status superior. O que chama a atenção, nesse caso, é que a postura por ele adotada parecia dizer respeito não só a um temperamento, humor ou traço pessoal, mas à existência de certos valores e ideias que ocupam um importante lugar no universo ideológico português. Numa sociedade em que os títulos nobiliárquicos foram abolidos há pouco mais de cem anos17 e em cujos espaços universitários vigem pronomes de tratamento como "Senhor Professor Doutor", posturas como a adotada por meu interlocutor

${ }_{17}$ Por força de lei, os títulos nobiliárquicos foram extintos em Portugal com a implantação da República em 5 de outubro de 1910. 
sinalizam, com clareza cristalina, a significativa valorização localmente atribuída aos títulos acadêmicos enquanto marcadores da estima social relativa ao prestígio.

Se, por um lado, o episódio a que acabo de me referir evidencia a valorização (inclusive pronominal) da hierarquia, cabe ressaltar que tal valorização coexiste com posturas notadamente diversas, tais quais a adotada pelo supervisor do meu estágio pós-doutoral. Indo de encontro às convenções locais, ele evitava ser chamado de senhor ou professor, solicitando, inclusive aos estudantes de graduação, que o tratassem simplesmente por "Zé". Pode-se objetar que talvez essa constitua uma situação excepcional, no mínimo rara. Em todo caso, entendo que, de algum modo, ela corresponde à contraparte dos princípios ideológicos acionados pelo jornalista. Nesse sentido, considero que as posturas respectivamente adotadas apontam para a necessidade de se ir além da "reificação tipologizante" (DUARTE, 2017) que concebe, de forma rígida e estática, a oposição formal entre holismo hierárquico e individualismo igualitário. Como assinala o próprio Dumont (1997), "o homem não apenas pensa, ele age. Ele não tem só ideias, mas valores" (DUMONT, 1997: 66) e estes constituem "algo mais do que sistemas normativos cristalizados e estáveis (...), sendo reconstruíveis, mesmo que apenas parcialmente, a partir de constelações de atitudes" (SILVA e MENDES, 2009: 175). A inevitável descontinuidade entre os planos das práticas e representações impede que a antinomia formal entre holismo e individualismo encontre um correspondente empírico pleno, uma vez que, para além de tal oposição, o que há, de fato, é uma espécie de gradiente no interior do qual os indivíduos se movem conforme as circunstâncias e os atores envolvidos. É precisamente aí, creio eu, que reside o caráter, a um só tempo, complexo, dinâmico e contextual das relações envolvendo formas hierárquicas e igualitárias de convivência social.

\section{Considerações finais}

Concomitantemente à pesquisa sobre a construção social da(s) violência(s) na imprensa lusitana, um dos objetivos da realização do estágio pós-doutoral em Portugal foi a consolidação da rede de pesquisadores associados ao convênio CAPES/FCT e o estabelecimento de novas parcerias institucionais junto aos pesquisadores do Centro de Estudos de Sociologia da Universidade Nova de Lisboa (Cesnova), bem como de outras instituições de ensino e pesquisa. Um importante movimento nesse sentido se deu a partir da minha participação no III Encontro de Portalegre, colóquio ocorrido em novembro de 2011, tendo como palco a Escola Superior de Educação Integrada, no Instituto Politécnico de Portalegre (Portugal). Na ocasião, tive a oportunidade de me haver com ricos debates acerca das demandas de direitos e reconhecimento em contextos diversos, como espaços escolares, hospitalares, prisionais ou outros caracterizados por experiências de vulnerabilidade. O evento, que resultou na publicação de uma coletânea (RESENDE e MARTINS, 2018) com os textos das comunicações apresentadas, serviu de cenário para o estabelecimento de uma profícua e aprazível interação entre pesquisadores portugueses e brasileiros que há algum tempo vinham mobilizando esforços para a construção de redes de cooperação acadêmico-científicas, tanto em âmbito nacional quanto internacional. Dentre as instituições ali representadas, pode-se mencionar, além da Universidade Nova de Lisboa, a Universidade de Lisboa, o Instituto Politécnico de Portalegre, a Universidade Federal Fluminense, a Universidade Federal do Rio de Janeiro e a Universidade Federal de Minas Gerais. 
É notório que, cada vez mais, a construção, ampliação e fortalecimento desse tipo de parceria vêm sendo de suma importância para o processo de internacionalização das Ciências Sociais, o que passa, necessariamente, pela internacionalização dos Cientistas Sociais. Particularmente no caso da Antropologia, tal processo encontra um importante suporte na vocação comparativa da disciplina que, desde a sua institucionalização, na segunda metade do século XIX, tem possibilitado a consecução de pesquisas notadamente diversificadas e, sob muitos aspectos, inovadoras. Não obstante, enquanto no passado a perspectiva comparativa estava atrelada a um movimento unidirecional, no qual alguns observavam e outros eram observados, hoje, os deslocamentos, fluxos e contrafluxos de antropólogos tornaram-se inexoráveis, o que tem aproximado pesquisadores oriundos dos mais diversos contextos acadêmicos e nacionais, favorecendo a constituição de múltiplos laços acadêmicos, bem como aprendizados pautados pelo salutar exercício do diálogo com a diferença. Sem sombra de dúvidas, experiências como a que serviu de base empírica para este artigo tendem a contribuir significativamente nesse sentido, posto que corroboram a máxima de que a comparação é o recurso que permite "vermos a nós mesmos em perspectiva" (DUMONT, 2000: 23).

Dentre os ganhos obtidos com o emprego do olhar comparativo (sobretudo, do que preconiza a dimensão contrastiva dos fenômenos sociais) está o de nos mostrar o equívoco que há em se tratar, como se fossem uma única e mesma coisa, ideias e valores que, apesar de receberem denominação semelhante, apresentam contornos e significados distintos, conforme os seus respectivos contextos de acionamento. É isso o que se verifica, por exemplo, quando confrontamos os sentidos atribuídos aos transportes públicos coletivos em Portugal e no Brasil. Enquanto, no primeiro caso, tais serviços são destinados a milhares de indivíduos indiferenciados, sejam eles quais forem, no segundo, especialmente no que concerne aos ônibus e trens, os traslados podem chegar a se confundir com o transporte de cargas, haja vista a má qualidade do atendimento conferido aos segmentos que deles necessitam em diferentes capitais do país. A esse respeito, devo confessar que, após o período passado no Exterior, o que mais me impactou no retorno ao Brasil foi o reencontro com o trânsito caótico do Rio de Janeiro, no qual se combinam, de um modo peculiar, a desigualdade típica de sociedades hierárquicas e a mais perversa resultante da ideologia individualista: o egoísmo. Igualmente impactante e reveladora dos princípios que estruturam o universo ideológico brasileiro foi a releitura de uma reportagem publicada alguns anos atrás com a qual, por acaso, voltei a ter contato tão logo desembarquei no Brasil. O texto noticiava o caso de um juiz que, sentindo-se ofendido por ter sido chamado de "você" pelo porteiro do condomínio em que residia, entrou com uma ação na Justiça para reivindicar que, sob pena de multa diária, todos os funcionários passassem a tratá-lo obrigatoriamente por "senhor" ou "doutor".

Com base no exposto, resta dizer, à guisa de conclusão, que a configuração de ideias e valores vigente em Portugal ora se assemelha, ora difere da existente entre os brasileiros, o que, no mais das vezes, pode produzir efeitos inusitados. No meu caso, por exemplo, tais similitudes e diferenças me remeteram, ao longo de pouco mais de seis meses, à condição ambígua de, em vários momentos, me sentir no Brasil, mesmo estando em Portugal, ao passo que, noutros (apesar dos laços históricos que unem os dois países), tinha a mais absoluta certeza de me encontrar numa sociedade distinta e distante da minha. 
Recebido em 10 de janeiro de 2020.

Aceito em 30 de abril de 2020.

\section{Referência}

DA MATTA, Roberto. "Sabe com quem está falando? Um ensaio sobre a distinção entre indivíduo e pessoa no Brasil". In: Carnavais, malandros e heróis: para uma sociologia do dilema brasileiro ( $4^{\mathrm{a}}$ ed.). Rio de Janeiro: Guanabara, 1990. pp. 179248.

DA MATTA, Roberto. Os discursos da violência no Brasil. Conta de mentiroso: sete ensaios de antropologia brasileira. Rio de Janeiro: Rocco, 1993. pp. 175-197.

DUARTE, Luiz Fernando Dias. O valor dos valores: Louis Dumont na antropologia contemporânea. Sociologia \& Antropologia, 7 (3): 735-772, 2017.

DUMONT, Louis. O individualismo: uma perspectiva antropológica da ideologia moderna. Rio de Janeiro: Rocco, 1985.

DUMONT, Louis. Homo hierarchicus: o sistema de castas e suas implicações. São Paulo: EDUSP, 1992.

DUMONT, Louis. Homo aequalis: gênese e plenitude da ideologia econômica. Bauru: EDUSC, 2000.

KANT DE LIMA, Roberto. "Carnavais, malandros e heróis: o dilema brasileiro do espaço público”. In: GOMES, Laura Graziela; BARBOSA, Lívia; DRUMOND, José Augusto (orgs.). O Brasil não é para principiantes: Carnavais, malandros e heróis, 20 anos depois. Rio de Janeiro: FGV, 2000. pp. 105-124.

MELLO, Marco Antônio da Silva; VOGEL, Arno. Lições da rua (ou quando a rua vira casa): algumas considerações sobre habito e diligo no meio urbano. Rio de Janeiro: LeMetro, 1981. pp. 1-15.

O'DONNELL, Guillermo. "E eu com isso? Notas sobre sociabilidade e política na Argentina e no Brasil”. In: Contrapontos: autoritarismo e democratização. São Paulo: Vértice, 1986. pp.121-155.

OLIVEIRA, Luís Roberto Cardoso de. Concepções de igualdade e cidadania. Contemporânea - Revista de Sociologia da UFSCAR, 1 (1): 35-48, 2011.

RESENDE, José; MARTINS, Alexandre (Orgs.). (Con)vivemos numa sociedade justa e decente? Críticas, envolvimentos e transformações. Porto: Fronteira do Caos, 2018.

SILVA, Pedro Alcântara da; MENDES, Hugo. "Valores sociais: família, política e ciência”. In: GARCIA, José Luís (org.). Estudos sobre os jornalistas portugueses - Metamorfoses e encruzilhadas no limiar do século XXI. Lisboa: ICS/Imprensa de Ciências Sociais, 2009. pp. 169-211. 


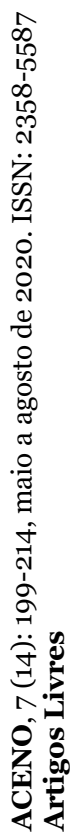

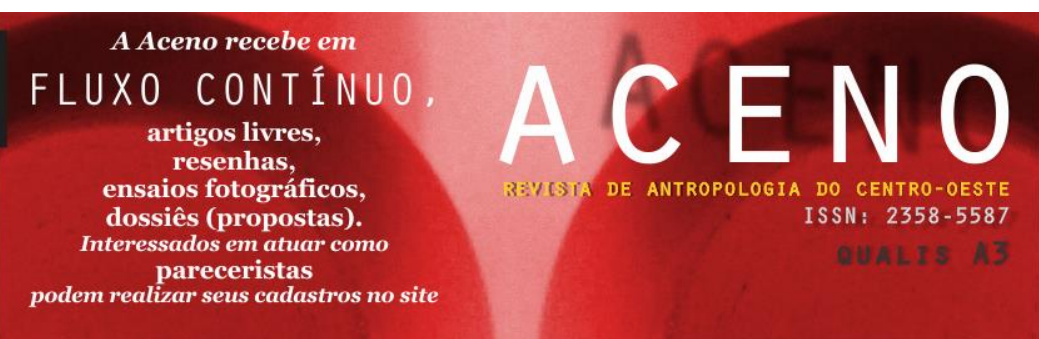

